\title{
IMPACT OF CLIMATE CHANGE ON AQUATIC ECOSYSTEM AND ITS BIODIVERSITY: AN OVERVIEW
}

\section{Sadguru Prakash}

Department of Zoology, M.L.K.P.G. College, Balrampur (U.P.), India

${ }^{*}$ Corresponding author: sadguruprakash@gmail.com

Article Info:

Review Article Received

02.09.2021

Reviewed

20.09.2021

Accepted

25.09.2021

\begin{abstract}
Climate change results from the increase in the greenhouse gas emission in the atmosphere and this comes as a consequence of various anthropogenic activities. The dissolution of $\mathrm{CO}_{2}$, which has the largest share among the greenhouse gases in terms of contribution in global warming, threatening the continuation of life on earth. Changing climate is of vital importance because of major impacts by influencing water resources and agricultural economy. Climate change stresses exert complex pressure on aquatic biodiversity and natural aquatic resources. Water temperature change may alter the metabolism and physiology of aquatic animals thereby affecting the growth, fecundity, feeding behavior, distribution, migration and abundance of fish as well as other aquatic animals.
\end{abstract}

Keywords: Aquatic biodiversity, Aquatic ecosystem, Climate change, Fishes.

\section{INTRODUCTION}

The word 'climate' refers to the long-term weather patterns within a defined region including temperature, humidity, rainfalls and wind amount. Weather refers to daily or weekly changes in the atmosphere, while climate is generally discussed, in terms of years, decades, centuries, and millennia. Today, the commonly used term 'climate change' represents any change in climate over a few decades, or millions of years, whether due to natural causes and/or as a result of human activities. Climate change alters entire ecosystems along with the living organisms that live there. Climate change has increasingly and profoundly threatened the global environment, biodiversity and sustainable human development, chiefly by altering global thermal regimes and the water cycle and causing acidification (Huang et al., 2021).
There are many factors that can cause a warning of our climate; for example more energy from the Sun and an increased greenhouse effect. Green house gases, such as water vapour, carbon dioxide and methane, occurs naturally in the atmosphere, but human activities also have directly increased the amount of carbon dioxide, methane and some other greenhouse gases in the environment.

Aquatic ecosystems are critical components of the global environment. In addition to being essential contributors to biodiversity and ecological productivity, they also provide a variety of services for human populations, including water for drinking and irrigation, recreational opportunities, and habitat for economically important fisheries. However, aquatic ecosystems have been increasingly threatened, directly and indirectly, by 
anthropogenic activities that need to be minimize (Ashok, 2015; Kumar and Verma, 2017; Arya, 2021).

As the Earth warms and temperature rises, regional climates are affected in various ways such as heavier monsoons in some areas and droughts in other areas, rising sea levels and crop failures. Reduced snowpack and shrinking glaciers in the mountains mean less melting snow flowing into rivers, reservoirs, and lakes for fish and wildlife, and less water available for drinking and irrigation. Warmer temperatures also produce increased evaporation, which leads to heavier rainfall and snowfall.

\section{CLIMATE CHANGE AND AQUATIC ECOSYSTEM}

Aquatic ecosystems have a limited ability to adapt according to climate change. Reducing the likelihood of significant impacts to these systems will be critically dependent on human activities that reduce other sources of ecosystem stress and enhance adaptive capacity.

Species have evolved to survive within certain temperature ranges and are able to tolerate variations in weather. The effects of climate change may push some species to the edge of extinction, while other species may flourish. Global warming disturbs the biological clock of various animals. Average global surface temperatures are projected to increase by 1.5 to $5.8^{\circ} \mathrm{C}$ by 2100 (Houghton et al., 2001).

Projected increase in temperature is expected to disrupt present patterns of plant and animal distribution in aquatic ecosystems. Increase in water temperature as a result of climate change will alter fundamental ecological processes and the geographic distribution of aquatic species (Efe and Bemigho, 2021). Such impacts may be ameliorated if species attempt to adapt by migrating to suitable habitat. For example, coldwater fish like trout and salmon are projected to disappear from large portions of their current geographic range. In contrast, many fish species that prefer warmer water, such as largemouth bass and carp, will potentially expand their ranges in European countries as surface water warms.
The productivity of aquatic ecosystems also will be significantly altered by increase in water temperature. Warmer water is naturally more productive, but the particular species that flourish may be undesirable or even harmful. For example, the large fish predators that require cool water may be lost from smaller lakes as surface water temperature warms, and this may indirectly cause more blooms of nuisance algae, which can reduce water quality and pose potential health problems. Thus, increase in temperature will cause a shift in the thermal suitability of aquatic habitats for resident species. In addition to its independent effects, temperature change will act synergistically with changes in the seasonal timing of runoff to freshwater and costal systems.

Changes in precipitation and runoff modify the amount and quality of habitat for aquatic organisms, and thus, they indirectly influence ecosystem productivity and diversity. Changes in seasonal patterns of precipitation and runoff will alter hydrologic characteristics of aquatic systems, affecting species composition and ecosystem productivity. Populations of aquatic organisms are sensitive to changes in the frequency, duration, and timing of extreme precipitation events, such as floods or droughts. Changes in the seasonal timing of snowmelt alter the stream flow, potentially interfering with the reproduction of many aquatic species. Thus, seasonal shifts in stream runoff will have significant negative effects on many aquatic ecosystems. Streams, rivers, wetlands, and lakes in the western mountains and northern plains are most likely to be affected, because these systems are strongly influenced by spring snowmelt and warming will cause to occur earlier in winter months.

The climate change influences both marine as well as freshwater ecosystems:

1. Marine Ecosystem: Climate change can impact on marine ecosystems through ocean warming, by increasing thermal stratification and reducing upwelling, sea level rise and through increase in wave height and frequency, loss of sea ice, increased risk of diseases in marine biota and 
decrease in $\mathrm{pH}$ and carbonate ion concentration of the surface oceans. Theoretically, nutrient speciation could be influenced by the lower $\mathrm{pH}$ expected this century. Decreases in both upwelling and formation of deep water and increased stratification of the upper ocean will reduce the input of essential nutrients into the sunlit regions of oceans and reduce productivity.

In coastal areas and margins, increased thermal stratification may lead to oxygen deficiency, loss of habitats, biodiversity and distribution of species, and impact on entire ecosystems. Changes to rainfall and nutrients flux from land may exacerbate these hypoxic events (Anonymous, 2007). Climate change is now known to be affecting the oceans. Polar bears are among the living beings that will be mostly affected by the decrease in the sea ice. As a result of habitat loss and decreasing of the habitat quality, a decrease of $30 \%$ population of polar bears is estimated.

The increase in greenhouse gases within the earth's atmosphere is set to change three fundamental variables:

- Reduced Total Carbonate Alkalinity: Total carbonate alkalinity of seawater will decrease as $\mathrm{CO}_{2}$ increases within the earth's atmosphere (Gattuso et al., 1998; Kleypas et al., 1999). This particular variable is expected to substantially change the acidity and carbonate ion pool of the global ocean. Doubling $\mathrm{CO}_{2}$ concentrations in the atmosphere will decrease the aragonite saturation state in the tropic by $30 \%$ by 2050 .

- Increased Sea Level: Changes in sea level have had major impacts on the abundance and particularly the distribution of both marine and terrestrial diversity. Sea level will rise as climate change pushes planetary temperature higher. This occurs due to the thermal expansion of sea water, melting of glacier, and changes to the distribution of ice sheets. The expected increase in sea level is approximately $9-29 \mathrm{~cm}$ over the next 40 years or 28-29 cm by 2090 (Church et al., 2001). According to Nicholls et al. (1999), sea level rise could cause the loss of up to $22 \%$ of the world's costal west lands by 2080. Combined with other human impacts, this number is likely to climb to a loss of $70 \%$ of the world's coastal wetlands by the end of the $21^{\text {st }}$ century.

- Sea Temperature Rise: Significant increase in heat content has not been distributed evenly. Sea temperature in turn influences the marine environment. Due to its direct effects on the density of seawater, changes in global temperatures can play directly upon the rates and directions of ocean water movement.

\section{Freshwater Ecosystem}

Climate change impact on inland aquatic ecosystems will range from the direct effects of the rise in temperature and carbon dioxide concentration to indirect effects through alterations in the hydrology resulting from the changes in the regional or global precipitation regimes and the melting of glaciers and ice cover (Anonymous, 2007).

The combination of rapid land use change, habitat alteration, pollution, nutrient enrichment, hydrological modifications, spread of invasive species, increasing levels of UV light, and a changing climate is viewed as a particular serious challenge to aquatic ecosystems. A warmer climate will result in greater evaporation from water surface and greater transpiration by plants which will result in a more vigorous water cycle. Further climate change will directly affect lake ecosystems through warmer temperature and changes to the hydrologic cycle.

Rapid climate change has many negative implications for the biodiversity of rivers and streams. Climate change may cause extension at several taxonomic levels. At the species level, those species that are highly restricted in their geographic ecologically are vulnerable to global extension. This is true for fish where there are regional differences in the proportional occurrence of specialized species are vulnerable to global extension.

\section{CLIMATE CHANGE AND AQUATIC BIODIVERSITY}

Biodiversity describes the range of living organisms in a given area considering the variety 
of life forms, the genes they contain, and the ecosystems they form (Ashok, 2016). Life forms within an ecosystem vary in their size and shape from the simplest unicellular prokaryote to the more complex multicellular eukaryotic organisms. Each organism plays an important role and contributes to ecosystem stability. The climate change has a huge impact on biodiversity and farmers' practice (Prakash and Srivastava, 2019; Mandal and Singh, 2020; Arya, 2021).

The diversity of life on earth is dramatically affected by human alterations of ecosystems. Biodiversity is continually transformed by a changing climate. Climatic conditions change across the face of the planet, sometimes slowly, sometimes in larger increments leading to rearrangements of biological associations. Now days, a new type of climate change, brought about by anthropogenic activities, is being added to this natural variability, threatening to accelerate the loss of biodiversity already under stress due to other human stresses. Approximately 70\% of the earth's surface is covered by water. Climate change is already changing the distribution and abundance of aquatic ecosystem. Even minor changes to water temperature will result in changes to the currents that flow across the earth's surface. So, the biodiversity conservation with environmental ethics is necessary for sustainable development and co-existence of both plants and animals (Ashok, 2017; Verma, 2019). For widespread biodiversity, ecological balance is must, which is necessary for the survival of entire biota including humans (Verma, 2017, 2018). Thus, biodiversity is a measure of the health of ecosystems and is the foundation of ecosystem services to which human wellbeing is intimately linked.

The climate change has impact on:

1. Deep sea biodiversity: The deep sea is a major reservoir of marine biodiversity. It is believed that the deep seabed supports more species than all other marine environment. Marine biodiversity and ecosystem are threatened by pollution, shipping, military activities and climate change, but today fishing presents the greatest threat. The greatest threat to biodiversity in the deep sea is bottom trawling. This type of high seas fishing is more damaging to seamounts and the cold-water corals they sustain. These habitats are home for several commercial bottom dwelling fish species.

2. Coastal fish diversity: Costal fisheries are critical resources for hundred of millions of people. Many scientists now point to the dramatic over exploitation of fisheries and the subsequent decline in fish stocks as the major factor in marine ecosystem change over the past two centuries (Jackson et al., 2001). Recent evidence has revealed that oceanographic and climatic variability has played a dominant role in fish stocks (Klyashtorin, 1998; Babcock et al., 2001; Attrill and Power, 2002).

The relationship between climate change and fish diversity and density is probably complex. In some cases, subtle changes may affect conditions and crucial changes in the life history of the fish species. The most widespread effects of climate occur on the primary and secondary production in marine ecosystems. Due to increase in carbon dioxide, the $\mathrm{pH}$ level of the sea water.

3. Crustaceans: The increase in the carbon dioxide concentration in water results in the decline of sea water's $\mathrm{pH}$, and thus the acidification of the sea water. This causes a negative effect on crustaceans. The outer skeletons of crustaceans consist of aragonite, a common form of calcium carbonate, and it can dissolve in acidic sea water. Extension of these small crustaceans found at the bottom of the nutrition chain can change the entire sea ecosystem. Oceanographic researchers point out that small crustaceans that are called krill and that feed on phytoplankton have decreased by $80 \%$ on average in the past 30 years.

4. Coral Reef: Tropical intertidal and sub tidal regions are dominated by ecosystems that are characterized by corals. This ecosystem supports the large populations of fish, birds, turtles and marine mammals. Reefs are places where many large living beings come to reproduce. Fishes which are densely caught by humans either 
reproduces at these reefs or use the food produced by these reefs. Decrease in light penetration, temperature and the carbonate alkalinity of sea water interfere in the formation of carbonate reefs. But due to climate change and other stresses, corals have undergone major changes over the past 20 years (Bryant et al., 1998) and these changes have been linked irrefutable to periods of warmer than normal sea temperature.

Coral bleaching occurs when corals rapidly lose the cells. Bleaching results in loses of important symbionts and colonies turning from brown to white. These alterations cause $90 \%$ changes in reef building coral communities. Corals form the essential framework within which multitudes of other species make their home. Fish that depends on corals for food, shelter or settlement cures may experience dramatic changes in abundance or go extinct. Thousands of other organisms are also vulnerable impacts on marine biodiversity.

\section{CONCLUSIONS}

The changes in climatic factors have a huge impact on the biodiversity of a region. Factors such as increasing temperatures and rising sea levels have impacted the marine and terrestrial ecosystems hugely leading to extinction of various species and many species have been categorized as vulnerable or are at point of being declared extinct. Factors such as deforestation, large scale development and construction like dams and other big developmental projects, clearing of forest land for agriculture and other non- agricultural uses have significantly impacted the biodiversity. The protection of biodiversity becomes crucial in present time. It is therefore important to understand the impacts of climate change on the biodiversity and mitigation strategies should be undertaken to reduce the damage caused by adverse effects of climatic change on biodiversity.

Conservation of biodiversity is the planning and management of biological resources in a way so as to secure their wide use and continuous supply, maintaining their quality, value and diversity. There is a need for prevention of extension through sound planning and management. There is an urgent need to step up efforts to mitigate the losses in biodiversity and implement long term measures to preserve this rich treasure. There is need to think about our future investments, whether we want to invest in future of mankind or their distribution. Biodiversity conservation cannot be brought about by enforcement of laws only.

Overall, these conclusions indicate climate change is a significant threat to the species composition and function of aquatic ecosystems. Indeed, as climate change alters ecosystem productivity and species composition, many unforeseen ecological changes are expected that may threaten the goods and services these systems provide to human. Thus, there is a need of biodiversity conservation because the biodiversity is nature's insurance policy against disasters.

\section{REFERENCES}

1. Anonymous (2007).Working Group II Report 'Impacts, Adaptation and Vulnerability': Intergovernmental Panel on Climate Change (IPCC), Switzerland.

2. Arya S. (2021). Freshwater Biodiversity and Conservation Challenges: A Review. Int. Journal of Biological Innovations. 3 (1): 74-78. https://doi.org/ 10.46505/IJBI.2021.3106

3. Ashok K. V. (2015). Values and Need of Biodiversity Conservation. Bioherald: An International Journal of Biodiversity and Environment. 5(1-2): 77-79.

4. Ashok K. V. (2016). Biodiversity: Its Different Levels and Values. International Journal on Environmental Sciences. 7(2): 143-145.

5. Ashok K. V. (2017). Environmental Ethics: Need to Rethink. International Journal on Environmental Sciences. 8(1): 7-9.

6. Attrill M. J. and Power M. (2002). Climatic influence on a marine fish assemblage. Nature.417(6886): 275-278.10.1038/417275a

7. Babcock H.A., Hare S.R. and Wooster W.S. (2001). Pacific Basin climate variability and patterns of northeast pacific marine fish production. Progress in Oceanography. 49(1): 257-282. 10.1016/S0079-6611(01)00026-X 
8. Bryant D., Burke L., McManus J. and Spalding M. (1998). Reefs at Risk: A map-based indicator of threats to the world's coral reefs. World Resources Institute,Washington, DC.

9. Church J. A., Gregory J. M., Huybrechts P., Kuhn M., Lambeck K., Nhuan M. T., Qin D. and Woodworth P.L. (2001). Changes in Sea Level, In: J.T Houghton, Y. Ding, D.J. Griggs, M. Noguer, P.J. Van der Linden, X. Dai, K. Maskell and C.A. Johnson (eds.): Climate Change 2001: The Scientific Basis: Contribution of Working Group I to the Third Assessment Report of the Intergovernmental Panel.http://hdl.handle.net/10013/epic.1508 1.d001

10. Efe Ogidiaka and Bemigho I. R. (2021). Fish Fauna Composition, Abundance and Distribution of Forcados River Estuary. Int. Journal of Biological Innovations. 3 (1): 139147. https://doi.org/ 10.46505/IJBI.2021.3113

11. Gattuso J.P., Frankignoulle M., Bourge I., Romaine S. and Buddemeier R.W. (1998). Effect of calcium carbonate saturation of seawater on coral calcification. Global Planetary Change. 18(1-2):37-47. 10.1016/S0921-8181(98)00035-6.

12. Houghton J.T., Ding Y., Griggs D.J., Noguer M., Linden P.J. vander, Dai X., Maskell K. and Johnson C.A. (2001). Climate Change 2001. The Scientific Basis:Contribution of Working Group I to the Third Assessment Report of the Intergovernmental Panel on Climate Change, Cambridge University Press, Cambridge, United Kingdom and New York, NY. 892p.

13. Huang M., Ding L., Wang J., Ding C. and Tao J. (2021). The impacts of climate change on growth: A summary of conducted studies and current knowledge. Ecological Indicators. 121.10.1016/j.ecolind.2020.106976

14. Jackson J.B.C., Kirby M.X., Berger W.H., Bjorndal K.A., Botsford L.W., Bourque B.J., Bradbury R.H., Cooke R., Erlandson J., Estes J.A., Hughes T.P., Kidwell S., Lange C.B., Lenichan H.S., Pandolfi J.M., Peterson C.H., Steneck R.S. and Tegner (2001). Historical overfishing and the recent collapse of coastal ecosystems. Science. 293 (5530): 629- 638.

15. Kleypas J.A., Buddemeier R.W., Archer D., Gattuso J.P., Langdon C. and Opdyke B.N. (1999). Geochemical consequences of increased atmospheric carbon dioxideon coral reefs. Science. 284(5411):118120.10.1126/science. 284.5411.118.

16. Klyashtorin L.B. (1998). Long-term climate change and main commercial fish production in the Atlantic and Pacific. Fisheries Research. 37:115-125.

17. Kumar Ajay and Verma A.K. (2017). Biodiversity loss and its Ecological impact in India. International Journal on Biological Sciences. 8(2): 156-160.

18. Mandal A.C. and Singh O.P. (2020). Climate Change and Practices of Farmers' to maintain rice yield: A case study. International Journal of Biological Innovations. 2(1): 42-51. https://doi.org/10.46505/IJBI.2020.2107.

19. Nicholls R.J., Hoozemans F.M.J. and Marchand M. (1999). Increasing food risk and wetland losses due to global sea level rise: Regional and global analyses. Global Environmental Change. 9(1):S69S87.https://doi.org/10.1016/S09593780(99)00019-9.

20. Prakash S. and Srivastava S. (2019). Impact of Climate Change on Biodiversity: An Overview. International Journal of Biological Innovations. 1(2): 60-65. https://doi.org/ 10.46505/IJBI.2019.1205.

21. Verma A. K. (2017). Necessity of Ecological Balance for Widespread Biodiversity. Indian Journal of Biology. 4(2):158-160.

22. Verma A. K. (2018). Ecological Balance: An Indispensable Need for Human Survival. Journal of Experimental Zoology, India. 21 (1): 407-409.

23. Verma A. Kumar (2019). Sustainable Development and Environmental Ethics. International Journal on Environmental Sciences. 10 (1): 1-5. 